\title{
HPLC METHOD FOR MEASUREMENT OF HUMAN SALIVARY $\alpha$-AMYLASE INHIBITION BY AQUEOUS PLANT EXTRACTS
}

\author{
IsTVÁn TAKÁCS, ${ }^{1,3}$ ÁKos TAKÁCS, ${ }^{2}$ ANIKÓ PÓSA ${ }^{1}$ and GYÖNGYI GYÉMÁNT ${ }^{3 *}$ \\ ${ }^{1}$ Department of Physiology, Anatomy and Neuroscience, University of Szeged, Szeged, Hungary \\ ${ }^{2}$ Department of Food Engineering, University of Szeged, Szeged, Hungary \\ ${ }^{3}$ Department of Inorganic and Analytical Chemistry, University of Debrecen, Debrecen, Hungary
}

(Received: October 3, 2016; accepted: December 1, 2016)

\begin{abstract}
Control of hyperglycemia is an important treatment in metabolic disorders such as type II diabetes and obesity. $\alpha$-Amylase, as the first enzyme of glucose release from dietary polysaccharides, is a potential target to identify new sources of novel anti-obesity and anti-diabetic drugs. In this work, different herbal extracts as $\alpha$-amylase inhibitors were studied by measuring the rate of the cleavage of a maltooligomer substrate 2-chloro-4-nitrophenyl- $\beta$-D-maltoheptoside. Measurement of chromophore containing products after reversed phase HPLC separation was used for $\alpha$-amylase activity measurement. Rates of hydrolysis catalysed by human salivary $\alpha$-amylase were determined in the presence and absence of lyophilised water extracts of eleven herbs. Remarkable bioactivities were found for extracts of Cinnamomum zeylanicum Blume (bark), Camellia sinensis L. (leaf), Ribes nigrum L. (leaf), Laurus nobilis L. (leaf), Vaccinium macrocarpon Aiton (fruit) and Syzygium aromaticum L. (bud). Determined $\mathrm{IC}_{50}$ values were in $0.017-41$ $\mu \mathrm{g} / \mathrm{ml}$ range for these six selected plant extracts. Our results confirm the applicability of this HPLC-based method for the quick and reliable comparison of plants as $\alpha$-amylase inhibitors.
\end{abstract}

Keywords: $\alpha$-amylase - inhibition - plant extract - HPLC - obesity - diabetes

\section{INTRODUCTION}

Obesity and the related health consequences such as diabetes, metabolic syndrome and hypertonia cause major worldwide concern [15]. Regular treatments necessitate diet, exercises or full lifestyle modification and have a high failure rate. Currently only a few anti-obesity drugs exist however they are not very effective [11]. Therefore, enzymes that catalyze digestion of dietary carbohydrates can be potential targets for therapeutic interventions. Human $\alpha$-amylases (1,4- $\alpha$-D-glucan-4glucanohydrolase) are endo enzymes, which catalyse random hydrolysis of starch, the main source of glucose in human diet [5]. Human salivary $\alpha$-amylase (HSA), the first enzyme of glucose absorption pathway, initiates the hydrolysis of $\alpha-(1,4)$ glycosidic bonds in the dietary starch into smaller oligosaccharides. Further digestion of starch and oligosaccharides takes place in the small intestine by human pancreatic $\alpha$-amylase

\footnotetext{
*Corresponding author; e-mail address: gyemant@science.unideb.hu
} 
(HPA) [13] a very closely related isoform of HSA with $97 \%$ sequence identity [4]. In this work HSA was selected as model enzyme of human $\alpha$-amylases.

As alternative to the currently used anti-diabetic drug acarbose, which has several undesirable side effects, there is an increased need to find natural compounds [18]. Several herb extracts were tested recently as potential $\alpha$-amylase and $\alpha$-glucosidase inhibitor. Cinnamon extracts markedly inhibited pancreatic $\alpha$-amylase and intestinal $\alpha$-glucosidase enzymes [2]. Gao et al. [7] published, that the $C$. sinensis extract displayed a favorable inhibitory activity on $\alpha$-amylase. It was reported that blackcurrant (Ribes nigrum) had inhibitory activity on $\alpha$-glucosidase and $\alpha$-amylase enzymes [16]. In addition, a study demonstrated beneficial effects of bay leaves (Laurus nobilis) on blood glucose, total cholesterol, LDL cholesterol, HDL cholesterol and triglycerid levels in subject with type 2 diabetes [12]. Based on experimental results, it can also be concluded, that anti-diabetic effect of bilberry (Vaccinium myrtillus) leaves might be due to the inhibition of the $\alpha$-amylase by the flavonoid quercetin [9]. Other results proved, that cranberry (Vaccinicum macrocarpon), containing $p$-coumaric acid and quercetin derivatives as the main phenolic compounds, inhibited $\alpha$-amylase activity [19]. A study of clove (Syzygium aromaticum) presented that strong correlation existed between the enzyme inhibitory activites and the phenolic content of the extracts [1]. The above-mentioned studies used starch as substrate and mainly reducing sugar determination after a certain time of incubation by dinitrosalycilic acid (DNS) method for $\alpha$-amylase activity measurement. The verification of the real initial rate determination usually was lacking. DNS method has several limitations and drawbacks: e.g. requires high volumes of samples, involves several steps and is labour-intensive and time-consuming [8].

The substrate, we used in this work, was 2-chloro-4-nitrophenyl- $\beta$-D-maltoheptoside (CNP-G7) [6]. This synthetic substrate overlaps with the active site of the HSA and behaves similar to the natural substrate. Action pattern of HSA revealed, that trimer (CNP-G3) is the main component (50\%) of the released three reducing end products. Chromophore aglycon allows UV detection at $302 \mathrm{~nm}$ with appropriate sensitivity. The $\beta$-glycosidic bond of aglycon is significant, because $\alpha$-amylase cannot cleave that, therefore reducing end products always contain a chromophore group [10]. Previous isothermic titration calorimetry (ITC) based assays were strengthened the hypothesis that the CNP-G7 mimic the starch, since it has similar $\mathrm{K}_{\mathrm{m}}$ values like natural starch in $\mathrm{HSA}$ catalysed enzyme reaction, and $\mathrm{IC}_{50}$ values of acarbose determined on starch and G7 were also similar [14].

In the present work, eleven plants were selected, based on above cited previous results, to test as $\alpha$-amylase inhibitors by measuring the initial rate of the cleavage of a maltooligomer substrate, 2-chloro-4-nitrophenyl- $\beta$-D-maltoheptoside. 


\section{MATERIALS AND METHODS}

\section{Enzyme}

Human salivary $\alpha$-amylase (EC 3.2.1.1, A0521 Sigma, $\alpha$-Amylase from human saliva Type IX-A, lyophilized powder, 1,000-3,000 units/mg protein). The enzyme gave a single band using SDS-PAGE and did not show $\alpha$ - or $\beta$-glucosidase activity. The $100 \mathrm{U}$ enzyme was dissolved in $1.0 \mathrm{ml}$ HPLC pure water and diluted tenfold.

\section{Substrate}

2-Chloro-4-nitrophenyl- $\beta$-D-maltoheptoside (CNP-G7) substrate was synthethised using a method described by Farkas et al. [6] and the product was fully characterised earlier. The purity and identity of substrate were determined by HPLC and MALDITOF MS (Fig. 1). Measured and calculated $\mathrm{m} / \mathrm{z}$ values for sodium adduct of CNP-G7 $\left[\mathrm{C}_{48} \mathrm{H}_{74} \mathrm{O}_{38} \mathrm{NCl}+\mathrm{Na}\right]^{+}$were 1330.34 and 1330.3475 , respectively. The resolution was monoisotopic, and isotopic pattern verified the presence of chlorine in the molecule.

\section{Buffer}

MES (2-(N-Morfolino)-etan sulfonic acid, Sigma M8250) $25 \mathrm{mM}$, was disolved in HPLC pure water (Molar Chemicals) and stabilised with $\mathrm{CaCl}_{2} \cdot 2 \mathrm{H}_{2} \mathrm{O}$ (Sigma) 5.0 $\mathrm{mM}$. $\mathrm{pH}$ was adjusted to 7.0 with $\mathrm{NaOH}$ (Molar Chemicals) or $\mathrm{HCl}$ (Molar Chemicals).

\section{Plant extracts}

Plants were purchased from the local herb store. Eleven plants species were examined as follows: Laurus nobilis L. (leaf), Sideritis montana L. (leaf), Vaccinium macrocarpon Aiton (fruit), Hibiscus sabdariffa L. (flower), Cyclopia genistoides L. Vent. (leaf), Rosmarinus officinalis L. (leaf), Syzygium aromaticum L. (bud), Cinnamomum zeylanicum Blume (bark), Phaseolus vulgaris L. (pod), Camellia sinensis L. (leaf), Ribes nigrum L. (leaf).

All plants were extracted with the same method. Ten $g$ of each dried herbs was boiled in $500 \mathrm{ml}$ distilled water at $100{ }^{\circ} \mathrm{C}$ for $20 \mathrm{~min}$ and the extracts were lyophilized using Christ Alpha1-4 freeze-drier for 36 hours. Same amount of the obtained residue $(5 \mathrm{mg})$ was solved in HPLC pure water $(1 \mathrm{ml})$ and centrifuged at $10,000 \mathrm{rpm}$ to eliminate non-water-soluble particles. Appropriate dilutions were made with buffer before inhibition measurements. 

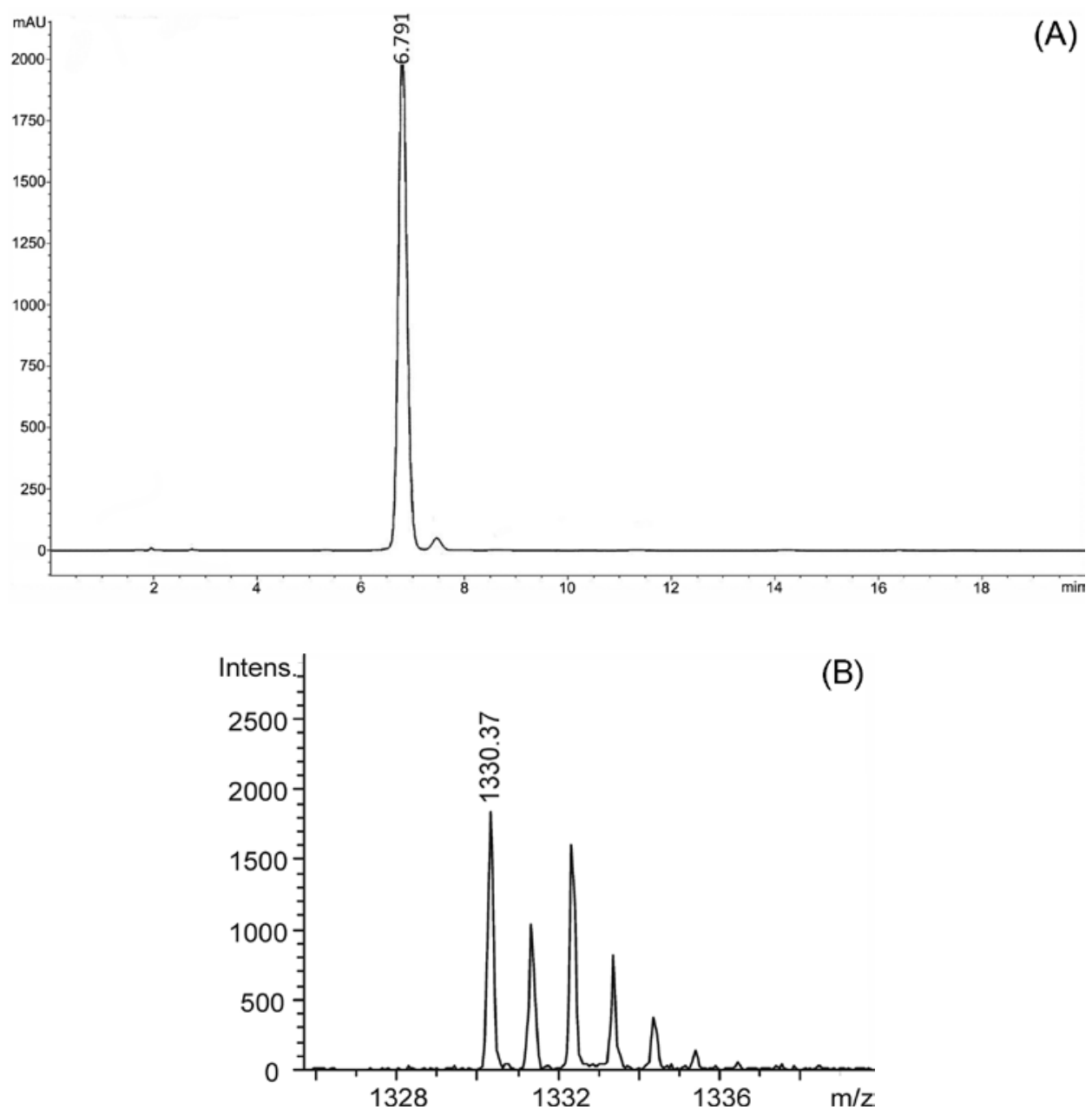

(B)

Fig. 1. Reversed phase HPLC chromatogram (A) and MALDI-TOF mass spectrum (B) of CNP-G7 substrate purified by preparative HPLC. Chromatographic conditions are defined in section 2.6

\section{MALDI-TOF mass spectrometry}

MALDI-TOF MS analysis of CNP-G7 was performed in positive-ion mode using a Bruker Biflex MALDI-TOF mass spectrometer equipped with delayed-ion extraction. Desorption/ionisation of the sample molecules was effected with a $337 \mathrm{~nm}$ nitrogen laser. Spectra from 100 laser shots were summarized using $19 \mathrm{kV}$ accelerating and 20 $\mathrm{kV}$ reflectron voltage. External calibration was applied using the $[\mathrm{M}+\mathrm{Na}]^{+}$peaks of cyclodextrins DP 6-8, m/z: 995.3067, m/z: 1157.3595, m/z: 1319.4124 Da, respectively. The spectrum was performed in 2,5-dihydroxy benzoic acid (DHB) matrix. 


\section{HPLC method for $\alpha$-amylase activity measurement}

For the assay, a solution of HSA $(100 \mathrm{U} / \mathrm{ml})$ was prepared in MES buffer and diluted tenfold. For each measurement $5 \mathrm{mM}$ CNP-G7 substrate was prepared freshly in MES buffer. Eight $\mu$ l enzyme $(10 \mathrm{U} / \mathrm{ml})$ and $400 \mu \mathrm{l}$ substrate was mixed with vortex and incubated at $37{ }^{\circ} \mathrm{C}$ for 5 minutes. Twenty $\mu$ of the solution was injected to the loop in every 15 minutes in total of 4 times. The device was an Agilent Infiniti 1100 instrument equipped with quaternary pump, degasser and manual sample injector. Separation was made using a Genesis C18 $(15 \mathrm{~cm} \times 4.6 \mathrm{~mm}$ $120 \AA 4 \mu \mathrm{m})$ column. $\mathrm{MeCN} / \mathrm{H}_{2} \mathrm{O}$ was used as isocratic eluent $(15: 85, \mathrm{v} / \mathrm{v})$ with flow rate of $0.8 \mathrm{ml} / \mathrm{min}$. The injection loop was $20 \mu \mathrm{l}$ and the column temperature was set to $37{ }^{\circ} \mathrm{C}$. Detection of CNP-G7 and CNP-oligomer products were carried out at $302 \mathrm{~nm}$. The amount of CNP-G3 was specified by the area of peak. Linearity $(0.01-5 \mathrm{mM}, \mathrm{s}=8944.76 \mathrm{r}=0.99932)$, system precision $(\mathrm{RSD}=0.88)$ and resolution $\mathrm{R}>2$ (3.0 and 2.36 for tetramer-trimer and trimer-dimer pairs, respectively) were determined as system suitability parameters. The reaction rate was determined by the representation of the area of CNP-G3 measured in four different times (Fig. 2). For the evaluation linear regression was used and the slope of fitted linear curve gave the enzyme activity.

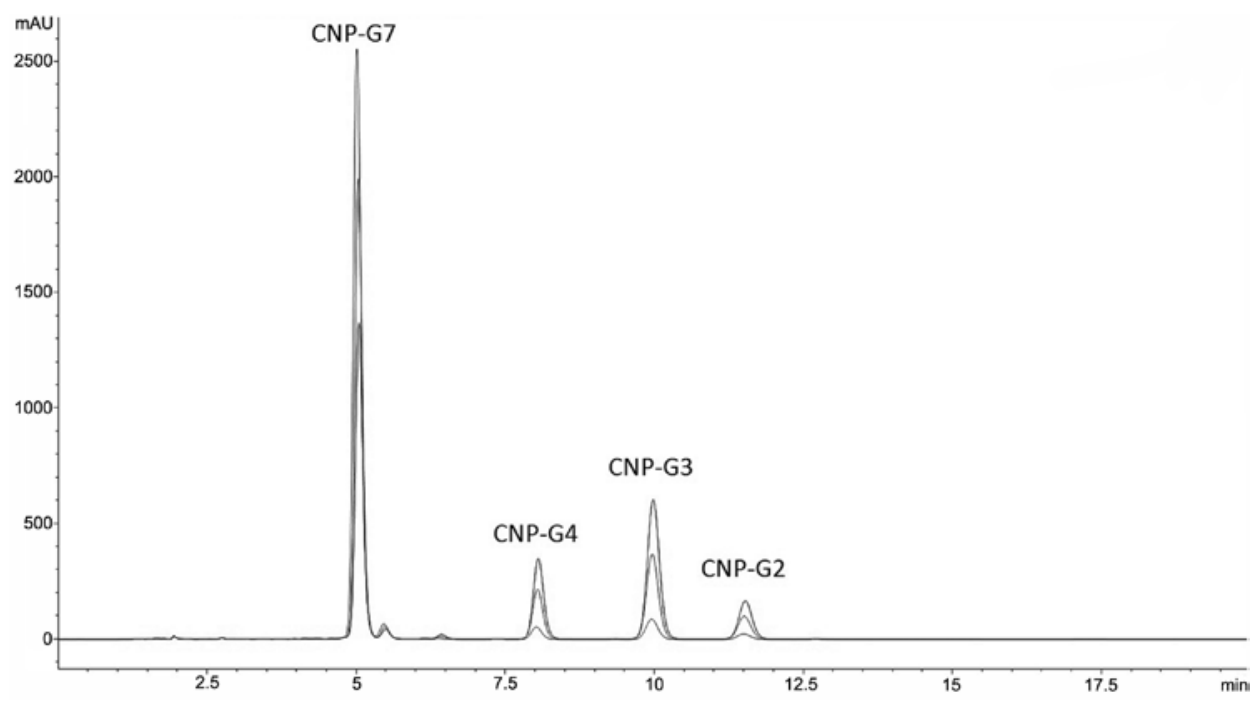

Fig. 2. Reaction rate measurement of HSA catalysed CNP-G7 hydrolysis without inhibitor using reversed phase HPLC separation of substrate and products. Chromatographic conditions are defined in 2.6, chromatograms were recorded in every 15 minutes. Increasing area data of CNP-G3 at 5, 20, 35 and 50 min were represented on Fig. 3 


\section{Inhibiton studies}

Inhibiton assays were performed using the same method for each plant. Extracts were dissolved in HPLC pure water to a concentration of $5 \mathrm{mg} / \mathrm{ml}$ as a stock solution. Eight $\mu \mathrm{l}$ of appropriate logarithmic dilutions of extracts and $8 \mu \mathrm{HSA}(10 \mathrm{U} / \mathrm{ml})$ were mixed with vortex and incubated for 4 minutes at $37^{\circ} \mathrm{C}$. After incubation the enzyme substrate reaction was started with the addition of $400 \mu$ l CNP-G7 (5 mM) solution and further incubated for 5 minutes. After 5 minutes $20 \mu \mathrm{l}$ of the solution was injected in to the column repeatedly in every 15 minutes, in total 4 times. For those plants that displayed good inhibition the $\mathrm{IC}_{50}$ values were determined at constant substrate and enzyme concentration using different concentration $(96-0.0096 \mu \mathrm{g} / \mathrm{ml})$ of plant extracts as inhibitor. For $\mathrm{IC}_{50}$ determination, the residual enzyme activity in the presence of inhibitor (calculated from the rate values) was plotted as a function of the logarithm of inhibitor concentration and the curve was fitted using non-linear regression.

\section{RESULTS}

After the water extraction of each plants the lyophilisation yielded various amount of dry product summarised in Table 1.

Enzyme activity was measured on HSA catalysed hydrolysis of CNP-G7 substrate in the presence of plant extracts using the same reaction conditions. Kinetic curves showed decreasing reaction rates due to the plant extracts of $96 \mu \mathrm{g} / \mathrm{ml}$ concentration (Fig. 3). Acarbose caused total inhibition of CNP-G7 hydrolysis under the same con-

Table 1

Yields of water extraction of plant samples

\begin{tabular}{|c|c|c|c|c|}
\hline \multicolumn{3}{|c|}{ Plant } & \multirow{2}{*}{$\begin{array}{l}\text { Yield of extraction } \\
\qquad(\mathrm{mg} / 10 \mathrm{~g})\end{array}$} & \multirow{2}{*}{ Colour } \\
\hline Name & Latin name & Part used & & \\
\hline Bay & Laurus nobilis & leaf & 1840 & light brown \\
\hline Blackcurrant & Ribes nigrum & leaf & 2400 & dark brown \\
\hline Cinnamon & Cinnamomum zeylanicum & cortex & 3520 & brown \\
\hline Clove & Syzygium aromaticum & buds & 2310 & brown \\
\hline Cranberry & Vaccinium macrocarpon & fruit & 2010 & red \\
\hline Green tea & Camellia sinensis & leaf & 2215 & light yellow \\
\hline Honeybush & Cyclopia genistoides & leaf & 1230 & brown \\
\hline Jamaica sorrel & Hibiscus sabdariffa & flower & 3440 & claret \\
\hline Mountain ironwort & Sideritis montana & leaf & 1600 & ocher \\
\hline Rosemary & Rosmarinus officinalis & leaf & 3834 & light yellow \\
\hline White bean & Phaseolus vulgaris & pod & 1730 & russet \\
\hline
\end{tabular}




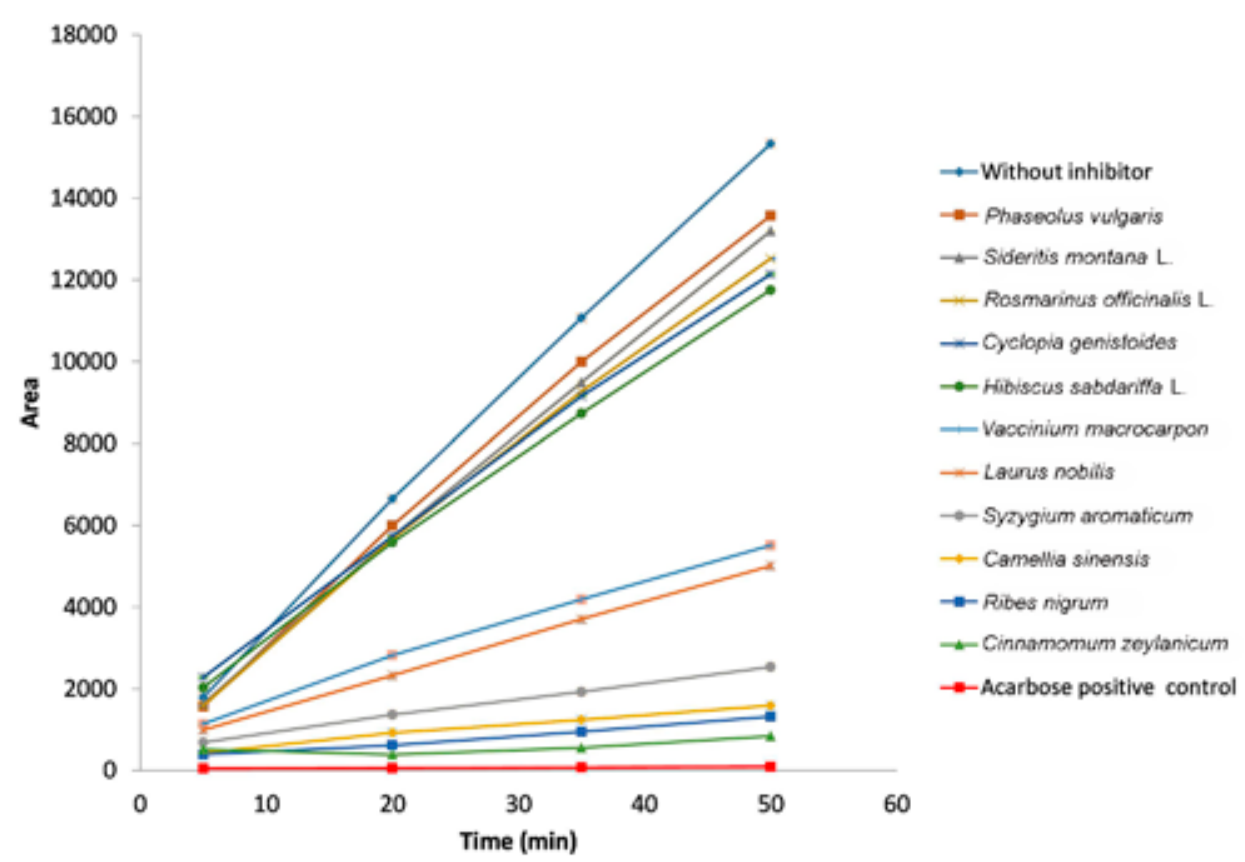

Fig. 3. Kinetic curves of HSA catalysed CNP-G3 production from CNP-G7 hydrolysis in the presence of various plant extracts

ditions. Six plants, namely Cinnamomum zeylanicum, Camellia sinensis, Ribes nigrum, Laurus nobilis, Vaccinium macrocarpon, Syzygium aromaticum, revealed remarkable bioactivity. Other 5, namely Sideritis montana, Hibiscus sabdariffa, Cyclopia genistoides, Rosmarinus officinalis and Phaseolus vulgaris, plants displayed moderate or low $\alpha$-amylase inhibitory potential.

Table 2

HSA inhibition effect of plant extracts

\begin{tabular}{|l|c|c|}
\hline \multicolumn{1}{|c|}{ Inhibitor } & $\mathrm{IC}_{50}(\mu \mathrm{g} / \mathrm{ml})$ & $\begin{array}{c}\text { Relative inhibition } \\
\left(\mathrm{IC}_{50} / \mathrm{IC}_{50} \text { of acarbose }\right)\end{array}$ \\
\hline Acarbose (control) & $0.006 \pm 0.0015$ & 1 \\
\hline Cinnamomum zeylanicum & $0.017 \pm 0.002$ & 2.8 \\
\hline Camellia sinensis & $0.22 \pm 0.08$ & 36 \\
\hline Ribes nigrum & $15 \pm 3$ & 2500 \\
\hline Laurus nobilis & $25 \pm 12$ & 4166 \\
\hline Syzygium aromaticum & $34 \pm 5$ & 5666 \\
\hline Vaccinium macrocarpon & $41 \pm 11$ & 6833 \\
\hline
\end{tabular}

$\mathrm{IC}_{50}$ values of plant extracts and acarbose, as positive control, measured on CNP-G7 substrate. 
HSA activity was measured at constant enzyme and substrate concentration using different dilutions of the selected six extracts. Inhibition potency, the concentration of inhibitor that decrease enzyme activity to the half $\left(\mathrm{IC}_{50}\right)$, was determined and summarised in Table 2.

\section{DISCUSSION}

During the past 25 years HPLC became undoubtedly the most important analytical method for identification and quantification of compounds, so it is available in almost all analytical lab. In parallel, the use of HPLC techniques in the study of enzymatic reactions has grown significantly. HPLC will be the method of choice for activity measurement if the components must be separated before quantitation, and detection of products is possible [20]. CNP-G7 hydrolysis by HSA met both criteria, since substrate and three released reducing end products were similar compounds (maltooligomers) and all contained chromophore group. The main product (CNP-G3) was quantified based on area data and reaction rates were calculated from linear part of kinetic curves.

Hot water extraction is similar to the normal application of these herbs as infusion or spices, which makes it more accessible and natural. Components of these extracts may achieve synergistic effects, therefore components were not prepared and examined separately.

The six plants selected showed great inhibitory effect on HSA, although the degree of inhibition is less than that measured for acarbose as a positive control. Two of them, cinnamon and green tea, were outstanding inhibitors with the low microgram/ $\mathrm{ml} \mathrm{IC} \mathrm{I}_{50}$ value in accordance with the earlier published literary observations. Our results also suggest that these two plants may have positive effect on managing the postprandial hyperglycemia via the control of the digestive enzymes. $\mathrm{IC}_{50}$ values of different cinnamons were published between $1.23-4 \mathrm{mg} / \mathrm{ml}$ by Adisakwattana et al. [2], who examined the effect of aqueous cinnamon extract on porcine pancreatic $\alpha$-amylase (PPA) catalysed starch hydrolysis reaction. These $\mathrm{IC}_{50}$ values were approximately twenty times higher than the value for acarbose $(0.098 \mathrm{mg} / \mathrm{ml})$, measured by the same method. Better results were published recently for hydro-alcoholic extract of cinnamon by Beejmohun et al. [3], where $\mathrm{IC}_{50}$ of 25 and $18 \mu \mathrm{g} / \mathrm{ml}$ was measured for cinnamon extract and acarbose, respectively. Their results of both in vitro PPA enzymatic assay with starch and in vivo starch tolerance test in rats demonstrated the effectiveness of cinnamon components on diabetes [3].

Green tea, a popular drink, is rich in polyphenols and has beneficial effects in the treatment of diabetes mellitus because of the strong inhibitory effect on $\alpha$-amylase and $\alpha$-glucosidase [7, 17]. Published $\mathrm{IC}_{50}$ of $4.0 \mathrm{mg} / \mathrm{ml}$ value on PPA indicates only low inhibition, although acarbose was found also a week inhibitor of PPA $\left(\mathrm{IC}_{50}=2.7\right.$ $\mathrm{mg} / \mathrm{ml})$ [7]. Similar $\mathrm{IC}_{50}(2.07 \mathrm{mg} / \mathrm{ml})$ was published for green tea on human pancreatic $\alpha$-amylase (HPA) recently, using starch as substrate and released glucose determination by hexokinase kit as amylase activity measurement method [17]. Green tea 
extract showed lower inhibition efficiency than acarbose or cinnamon extract but it still can be classified as a promising inhibitor.

We measured similar inhibition potency $\left(\mathrm{IC}_{50}\right.$ range between $10-50 \mu \mathrm{g} / \mathrm{ml}$ ) for extracts of blackcurrant, bay, clove leaves and cranberry fruit. Polyphenol rich extract of berry fruits are known as amylase inhibitors [16, 19], but leaves of blackcurrant were not examined earlier. Extract of bay leaves in human and animal pilot studies decreased postprandial hyperglycemia, but $\alpha$-amylase inhibition was not studied, so far [12]. Components, extracted by organic solvents from clove, inhibited PPA dosedependent manner. $\mathrm{IC}_{50}$ of 497.27 and $553.77 \mu \mathrm{g} / \mathrm{ml}$ was determined for aceton and ethylacetate extracts, respectively, using starch as substrate [1]. In an other study $\mathrm{IC}_{50}$ of 37.1 and $36.2 \mu \mathrm{g} / \mathrm{ml}$ were measured for methanolic extracts of cinnamon and clove, similar to value $34.5 \mu \mathrm{g} / \mathrm{ml}$ of acarbose [21]. Our results verified the inhibition, the difference of $\mathrm{IC}_{50}$ values can be explained by the different methods of measurement. Unfortunately, the previous results found in the literature are difficult to compare with each other because different enzymes, substrates, activity measurement and extraction methods were used.

Our results suggest that using cinnamon bark as a spice can potentially be useful to decrease glucose release from starch containing foods, since inhibition effect of components extractable with water from $1.2 \mathrm{~g}$ of cinnamon powder should be similar as effect of $150 \mathrm{mg}$ (daily dose) acarbose. Calculation was made based on $\mathrm{IC}_{50}$ values of acarbose and cinnamon extract and extraction yield of cinnamon. The other five plants can be taken into consideration as a source of inhibitor compounds, and the plant extracts may be useful as a component of dietary supplements for weight loss or antidiabetic therapy.

Our results confirm the applicability of our HPLC-based kinetic method as a highly accurate and reliable way of determination of herbal extracts inhibitory activity on $\alpha$-amylase.

\section{ACKNOWLEDGEMENTS}

We are grateful to Prof. Dr. Judit Hohman and Dr. Dezső Csupor (University of Szeged) for the collection of plant samples. The work was supported by the ÚNKP-16-4 New National Excellence Program of the Ministry of Human Capacities (Aniko Posa).

\section{REFERENCES}

1. Adefegha, S. A., Oboh, G. (2012) In vitro inhibition activity of polyphenol-rich extracts from Syzygium aromaticum (L.) Merr. \& Perry (Clove) buds against carbohydrate hydrolyzing enzymes linked to type 2 diabetes and $\mathrm{Fe}^{2+}$-induced lipid peroxidation in rat pancreas. Asian Pac. J. Trop. Biomed. 2, 774-781.

2. Adisakwattana, S., Lerdsuwankij, O., Poputtachai, U., Minipun, A., Suparpprom, C. (2011) Inhibitory activity of cinnamon bark species and their combination effect with acarbose against intestina 1 alphaglucosidase and pancreatic alpha-amylase. Plant Foods Hum. Nut. 66, 143-148.

3. Beejmohun, V., Peytavy-Izard, M., Mignon, C., Muscente-Paque, D., Deplanque, X., Ripoll, C., Chapal, N. (2014) Acute effect of Ceylon cinnamon extract on postprandial glycemia: alpha-amylase 
inhibition, starch tolerance test in rats, and randomized crossover clinical trial in healthy volunteers. BMC Complement. Alter. Med. 14, 351.

4. Brayer, G. D., Luo, Y., Withers, S. G. (1995) The structure of human pancreatic alpha-amylase at 1.8 A resolution and comparisons with related enzymes. Protein Sci. 4, 1730-1742.

5. Brayer, G. D., Sidhu, G., Maurus, R., Rydberg, E. H., Braun, C., Wang, Y., Nguyen, N. T., Overall, C. M., Withers, S. G. (2000) Subsite mapping of the human pancreatic alpha-amylase active site through structural, kinetic, and mutagenesis techniques. Biochemistry 39, 4778-4791.

6. Farkas, E., Janossy, L., Harangi, J., Kandra, L., Liptak, A. (1997) Synthesis of chromogenic substrates of alpha-amylases on a cyclodextrin basis. Carbohydr. Res. 303, 407-415.

7. Gao, J., Xu, P., Wang, Y., Wang, Y., Hochstetter, D. (2013) Combined effects of green tea extracts, green tea polyphenols or epigallocatechin gallate with acarbose on inhibition against alpha-amylase and alpha-glucosidase in vitro. Molecules 18, 11614-11623.

8. Gusakov, A. V., Kondratyeva, E. G., Sinitsyn, A. P. (2011) Comparison of two methods for assaying reducing sugars in the determination of carbohydrase activities. Int. J. Anal. Chem, article ID: 283658.

9. Helmstädter, A., Schuster, N. (2010) Vaccinium myrtillus as an antidiabetic medicinal plant research through the ages. Pharmazie 65, 315-321.

10. Kandra, L., Gyemant, G. (2000) Examination of the active sites of human salivary alpha-amylase (HSA). Carbohydr. Res. 329, 579-585.

11. Kang, J. G., Park, C. Y. (2012) Anti-obesity-drugs: A review about their effects and safety. Diabetes Metab. 36, 13-25.

12. Khan, A., Zaman, G., Anderson, R. A. (2009) Bay leaves improve glucose and lipid profile of people with type 2 diabetes. J. Clin. Biochem. Nutr. 44, 52-56.

13. Lehmann, U., Robin, F. (2007) Slowly digestible starch - its structure and health implications: A review. Trends Food Sci. Tech. 18, 346-355.

14. Lehoczki, G., Szabo, K., Takacs, I., Kandra, L., Gyemant, G. (2016) Simple ITC method for activity and inhibition studies on human salivary alpha-amylase. J. Enzyme Inhib. Med. Ch. 6, 1648-1653.

15. Marsh, K., Brand-Miller, J. C. (2008) State of the art reviews: Glycemic index, obesity, and chronic disease. Am. J. Lifestyle Med. 2, 142-150.

16. McDougall, G. J., Stewart, D. (2005) The inhibitory effects of berry polyphenols on digestive enzymes. BioFactors 23, 189-195.

17. Miao, M., Jiang, B., Jiang, H., Zhang, T., Li, X. (2015) Interaction mechanism between green tea extract and human alpha-amylase for reducing starch digestion. Food Chem. 186, 20-25.

18. Najafian, M., Ebrahim-Habibi, A., Yaghmaei, P., Parivar, K., Larijani, B. (2010) Core structure of flavonoids precursor as an antihyperglycemic and antihyperlipidemic agent: an in vivo study in rats. Acta Biochim. Pol. 57, 553-560.

19. Pinto, Mda, S., Ghaedian, R., Shinde, R., Shetty, K. (2010) Potential of cranberry powder for management of hyperglycemia using in vitro Models. J. Med. Food. 13, 1036-1044.

20. Rossomando, E. F. (1998) HPLC in enzymatic analysis. In: Methods of Biochemical Anaysis, John Wiley \& Sons, pp. 1-24.

21. Salehi, P., Asghari, B., Esmaeili, M. A., Dehghan, H., Ghazi, I. (2013) $\alpha$-Glucosidase and $\alpha$-amylase inhibitory effect and antioxidant activity of ten plant extracts traditionally used in Iran for diabetes. J. Med. Plant. Res. 7, 257-266. 